\title{
Use of primary literature in the undergraduate analytical class
}

\author{
Michelle L. Kovarik ${ }^{1}$
}

Published online: 23 March 2016

(C) Springer-Verlag Berlin Heidelberg 2016

While textbooks provide detailed explanations that are designed for student comprehension, these texts rarely expose students to cutting edge science and the processes used to conduct it. Additionally, textbooks divide a broad range of topics into sections, sometimes obscuring the connections that exist between these topics in practice. In contrast, the primary literature, while written for the specialist, provides a model for the actual methods by which scientific research is conducted, along with rich data sets and arguments that draw on multiple concepts from the chemistry curriculum. The primary literature can be used in a number of ways in undergraduate coursework (for good overviews, see refs. [1] and [2]), and instructors may include primary literature reading assignments in their teaching in order to achieve a variety of goals. These assignments may aid students in making connections between multiple course topics [3, 4], applying concepts from lecture to new scenarios [5], and learning topics not otherwise covered in a course [1]. Additionally, primary articles often engage student interest since they reflect real-world scientific problems and their solutions. Below, I review the science education literature on student engagement with the primary literature, describe the design of assignments I use in my teaching, and offer a few suggestions for implementing primary literature assignments in analytical chemistry and instrumental analysis courses.

Michelle L. Kovarik

michelle.kovarik@trincoll.edu

1 Department of Chemistry, Trinity College, 300 Summit St., Hartford, CT 06106, USA

\section{Research on student engagement with the primary literature}

Science education research suggests that reading the primary literature enhances student learning in several ways. Exposure to the peer-reviewed literature improves student writing by providing concrete models; interpretation of figures gives students the opportunity to apply course concepts to authentic data; and assessment of claims in articles hones critical thinking skills as students evaluate evidence and critique author arguments. Students who have read primary literature change the way they approach articles in the future, spending more time examining figures and comprehending subsequent articles more completely $[1,3$, 6]. Students who read the literature as part of a classroom assignment also show attitudinal and epistemological changes: they are more confident in their ability to interpret data and demonstrate a greater appreciation for the nature of science [1, 3, 7-9]. These outcomes address goals espoused by many instructors as well as the American Chemical Society's Committee on Professional Training [10]. However, achievement of these outcomes requires students and instructors to overcome several challenges associated with novices' engagement with primary literature. Research indicates that the high density of abstract and technical information and the impersonal, argumentative writing style of scientific articles are particularly challenging for students [11]. Additionally, it is critical that students understand the techniques used to acquire data before reading an article $[12,13]$. The latter challenge suggests that primary literature assignments will work well in an analytical chemistry or instrumental analysis course, where the lecture topics are methods- and instrument-driven, thereby preparing students to apply their knowledge of techniques to specific published applications. 
Two general models exist for scaffolding student reading of the primary literature to address these challenges: a general assignment that can be applied to any article and a specific set of questions that address a specific paper. The first model is often based on the common structure of scientific research articles [14-16]. For example, questions posed to students might include "Why was the experiment performed?" [16] or "What results did the investigator collect?" [14]. Depending on instructor goals, the general scaffold may emphasize rhetoric [1, 17, 18], data interpretation, or overall comprehension. For example, a scaffold emphasizing rhetoric might ask students to analyze an article by identifying evidence versus conclusions $[1,17]$. Other assignments focus on interpretation of figures $[6$, 19], student dialogue with the article text [20], or translation of the article into a format accessible to a layperson [3]. Another interesting variation is to have students read the articles during the first 15 min of class, focusing on abstracts and figures, then filling in details $[21,22]$. While this method necessarily results in more surface-level comprehension, it trains students to read the primary literature as experts do, focusing on informationrich portions of an article. Indeed, assignments based on a general scaffold tend to emphasize the commonalities of all scientific articles and their shared structure.

The second model uses specific questions based on particular articles, perhaps in addition to more generally applicable questions [1, 23]. For example, in a biochemistry course, students may read an article on DNA replication and answer questions such as "The authors of this article used both an 18-mer and a 23-mer. What are these and why did they use both? Which figures show data with the 18-mer and which show data collected using the 23-mer?" [1]. Assignments built on these specialized scaffolds delve deeply into the science of the articles, often encouraging students to draw connections between concepts discussed in class and the specific data presented in the article. A variation of this model, the CREATE method, is based on progressive analysis of a series of papers from the same research laboratory $[7,8]$. In general, assignments based on this second model are more time-consuming to create since questions must be tailored to the article in question; however, this tailoring also allows the instructor to guide students in developing connections between course material and article content. As a result, the choice of scaffold should be made with attention to the instructional goals of the assignment.

\section{Design of assignments}

While many articles have been written about using the primary literature as a teaching tool, few papers focus on its use in chemistry classes [1, 5, 24], and none emphasizes analytical chemistry or instrumental analysis in particular. With this in mind, I designed a series of assignments for use in undergraduate-level quantitative analysis, analytical chemistry, and instrumental analysis courses. My main goals were to engage students in interpretation of authentic research results and to encourage integration of concepts from throughout the analytical chemistry curriculum. Selecting appropriate articles was challenging and time-consuming. (Reference [2] has several useful suggestions for ways to find articles, including being watchful for good articles during one's routine review of the literature, identifying seminal papers or contemporary articles that cite these seminal works, and tracking down primary sources for stories in the popular news media.) Ideally, articles will be accessible and interesting to students, model quality experimental design and scientific writing, and include multiple concepts from the unit or the course (Table 1). For example, for an assignment on spectroscopy (Table 2), we read an article on information transmission via atomic emission beacons. While some components of the assignment discuss spectroscopic details, students also consider signal-to-noise ratio and signal processing.

Assignment questions are structured to address a multiplicity of goals. Straightforward factual questions are useful for establishing the main points of the paper and encouraging students to recognize course concepts in new context. However, literature assignments should also give students the opportunity to think deeply about the material and to connect multiple concepts from across the course. These more open-ended, higher-order questions result in the most productive discussion. As a result, assignments can be divided into two parts: a set of objective out-ofclass questions and several more involved questions for discussion in small groups during class. This strategy of assigning more straightforward questions as outside of class preparation and undertaking more conceptually challenging activities in class has been used previously [1], and Bloom's taxonomy [25] is a useful guide in determining which questions to use in-class versus out-of-class. For example, out-of-class question 1 in the sample assignment (Table 2) simply establishes that students comprehend the main topic of the article, and out-of-class questions 2 and 3 prompt students to recall information about atomic emission. Out-of-class questions 6, 7, and 8 ask students to apply concepts from class to the new context of the paper. These types of questions correspond to Bloom's taxonomy levels I-III (remembering, understanding, and applying). In contrast, the inclass discussion questions require higher-order thinking skills (Bloom's levels IV-VI). For example, in-class question 1 requires students to analyze the published data and evaluate whether the desired increase in detection limit is feasible.

In my experience, discussions of the in-class questions are best conducted in small groups of 3-5 students with a wholeclass wrap-up at the end of the period or between questions. To ensure that everyone is prepared to develop their ideas further during small group discussions, I reserve 5-10 min at the start of class to respond to student questions about the outof-class assignment. Additionally, I circulate during the small group discussions, clarifying or correcting as needed. For 
Table 1 Assignments and topics covered

\begin{tabular}{|c|c|c|}
\hline Assignment & Article & Topics included \\
\hline Comparing methods & $\begin{array}{l}\text { DL Phillips, IR Tebbett, and RL Bertholf, "Comparison of HPLC and GC-MS for measurement } \\
\text { of cocaine and metabolites in human urine" J. Anal. Toxicol. 1996, 20, 305-308 }\end{array}$ & $\begin{array}{l}\text { Figures of merit } \\
\text { Internal standards } \\
\text { Statistics } \\
\text { Scientific writing }\end{array}$ \\
\hline Acid-base chemistry & $\begin{array}{l}\text { M Dittrich and S Sibler, "Cell surface groups of two picocyanobacteria strains studied by zeta } \\
\text { potential investigations, potentiometric titration, and infrared spectroscopy," J. Coll. Int. Sci. } \\
\mathbf{2 0 0 5}, 286,487-495\end{array}$ & $\begin{array}{l}\mathrm{pH} \\
\text { Isoelectric point } \\
\mathrm{p} K_{\mathrm{a}} \\
\text { Titrations } \\
\text { Buffers } \\
\text { Biochemistry } \\
\text { Scientific writing }\end{array}$ \\
\hline Separation science & $\begin{array}{l}\text { B Wei, DS Malkin, and MJ Wirth, "Plate heights below } 50 \mathrm{~nm} \text { for protein electrochromatography } \\
\text { using silica colloidal crystals," Anal. Chem. 2010, } 82,10216-10221\end{array}$ & $\begin{array}{l}\text { van Deemter equation } \\
\text { Resolution } \\
\text { Electroosmosis } \\
\text { Nanoscience }\end{array}$ \\
\hline Spectroscopy* & $\begin{array}{l}\text { CN LaFratta, I Pelse, JL Falla, MA Palacios, M Manesse, GM Whitesides, and DR Walt, } \\
\text { "Measuring atomic emission from beacons for long-distance chemical signaling," Anal Chem. } \\
\mathbf{2 0 1 3}, 85,8933-8936\end{array}$ & $\begin{array}{l}\text { Atomic emission } \\
\text { Wavelength selection } \\
\text { Signal processing } \\
\text { Signal-to-noise ratio } \\
\text { Limits of detection }\end{array}$ \\
\hline Mass spectrometry & $\begin{array}{l}\text { RA Sowell, KE Hersberger, TC Kaufman, and DE Clemmer, "Examining the proteome of } \\
\text { Drosophila across organism lifespan," J. Proteome Res., 2007, 6, 3637-3647 }\end{array}$ & $\begin{array}{l}\text { Strong cation exchange } \\
\text { Electrospray ionization } \\
\text { Ion mobility } \\
\text { Mass analyzers } \\
\text { Resolving power } \\
\text { Tandem MS } \\
\text { Quantitative MS } \\
\text { Bioinformatics }\end{array}$ \\
\hline Electrochemistry & $\begin{array}{l}\text { PEM Phillips, GD Stuber, MLAV Heien, RM Wightman, and RM Carelli, "Subsecond } \\
\text { dopamine release promotes cocaine seeking," Nature, 2003, 422, 614-618 }\end{array}$ & $\begin{array}{l}\text { Electrodes } \\
\text { Cyclic voltammetry } \\
\text { Redox chemistry } \\
\text { Signal-to-noise ratio } \\
\text { Selectivity and controls }\end{array}$ \\
\hline
\end{tabular}

*See sample assignment in Table 2

example, for the spectroscopy assignment, the students discuss the "distance limit of detection" for the atomic emission beacons, but the concept of a "distance limit of detection" is unprecedented in the class. By circulating, I can address any questions about how the distance LOD differs from a concentration LOD or mass LOD as they arise. Generally, I have each group of students discuss every question; however, the "jigsaw" method is also effective [26]. In this format, small groups of students are assigned to a particular in-class discussion question on which they reflect and become expert before class. At the start of class, students who studied the same question meet briefly to discuss their interpretations and develop a consensus explanation. Students are then shuffled to form new groups in which each member is expert on a different question. Each "expert" presents their answer to their particular question and answers their classmates' questions [13]. This jigsaw method can usually be completed in less time since each student discusses only one question in detail, and novice students, who might be overwhelmed by the paper as a whole, may benefit from focusing their attention on a subsection of the article.

Student learning is assessed during class discussions and by examinations. The in-class discussion provides an opportunity for formative assessment of students' interpretation of the paper. In exams, multi-part questions based on data from the primary literature are used for summative assessment. The data presented are not typically from the papers read in-class; however, the questions draw upon the same skill set developed during in-class discussions. For example, after doing the assignment for mass spectrometry, students might be given data from ref. [27] and asked to determine the resolving power and mean free path of ions in the mass spectrometer. On the basis of these answers, students then explain whether they think the instrument described in the paper is a Q-TOF or a triple quad and suggest a suitable fragmentation method for tandem MS experiments on this instrument. Like the questions in the article assignments, these questions span 
Table 2 Sample assignment: spectroscopy. (Adapted from ref. [28])

Selected out-of-class questions from spectroscopy assignment [28]

1 Define "infochemistry"

2 In this paper, the salts are atomized by combustion (i.e., a flame). What other methods are used for atomization and excitation in atomic emission?

3 A methanol and air flame (like the one used here) obtains a maximum temperature of about $2000{ }^{\circ} \mathrm{C}$. What is the maximum temperature of an ICP? Why are high temperatures necessary for AES?

6 In Fig. 2, what components act as wavelength selectors for the custom telescope? What wavelength selector is usually used in AES instrumentation? Explain the advantages of these two types of wavelength selectors for each application

7 In Fig. 3, what signal processing method was used on the data? What are the advantages of this method for this application?

8 Estimate the signal-to-noise ratio of the processed cesium signal in the top right panel of Fig. 6 in the article.

9 Go to the NIST Handbook of Basic Atomic Spectroscopic Data and look up the most intense persistent strong line(s) between 700 and $900 \mathrm{~nm}$ for $\mathrm{Na}, \mathrm{Li}$, and $\mathrm{Ca}$ in air. The symbol "P" next to the intensity indicates persistent lines, which are detectable even for low concentrations of the element in the presence of other species. http:/www.nist.gov/pml/data/handbook/index.cfm\#

10 Peruse the bandpass filters available from Spectrofilm.com (the vendor used for parts in this manuscript). What is the narrowest range of wavelengths that can be passed by these commercial filters? How does this compare to the width of an atomic emission line?

Selected in-class questions from spectroscopy assignment [28]

1 Consider Fig. 4.

a) Show the calculation used to determine the distance limit of detection of $1.7 \mathrm{~km}$

b) By what factor would the intensity of the atomic emission need to be increased to double the distance limit of detection?

c) Is it reasonable to expect that this increase in intensity could be achieved by increasing the concentration of the metal salts? Explain your answer

4 The authors suggest that greater information density could be achieved by adding $\mathrm{Na}, \mathrm{Li}$, and $\mathrm{Ca}$ to the signal. Do you think that this would be feasible? Support your answer using information from out-of-class questions 9 and 10

5 The authors suggest that this beacon could be used to transmit data in resource-poor environments, such as natural disaster sites. Evaluate this application given the information in the manuscript

Bloom's taxonomy and ask students to apply concepts from class to new data from real-world applications.

\section{Conclusions}

Six assignments suitable for analytical chemistry and instrumental analysis courses (Table 1) are freely available on the Active Learning site of the Analytical Sciences Digital Library [28]. In adapting these materials, some considerations might be topical overlap with your curriculum, class size, class period length, and student preparation. The assignments focus on core ideas from commonly used textbooks, but each course is unique. For this reason, the assignments are available as Word documents for easy editing. While I have typically used these assignments in small classes (5-12 students), other instructors routinely use the primary literature in larger courses. Similarly, I have used these assignments in 50-min class periods, but the discussion is typically robust until the end of class and occasionally we do not complete every in-class question. For this reason, the assignments would likely scale well to longer periods or multiple class meetings. Finally, student preparation for engaging the primary literature will vary between institutions and within an institution depending on individual students' previous exposure; however, I have used these assignments at a large public institution and a small liberal arts college. It may be helpful to use part of a prior class period to introduce unfamiliar concepts. This is particularly important, for example, when my students read the proteomics paper (Table 1), since not all have taken biochemistry. Since implementing these assignments, student feedback on end of semester evaluations has included comments such as "Questions made you think outside of the box instead of regurgitating information" and "The journal article questions allowed us to think of the article in more general context as well as how it related to the class material presented, so those were great!" I hope that the information provided here and the materials on the ASDL site will lead to similar outcomes in your courses.

Acknowledgments The author thanks Prof. Jill Robinson of Indiana University and Prof. Tom Wenzel of Bates College for helpful comments on the assignments discussed here. This work was supported by the SPIRE program at the University of North Carolina (NIH K12GM000678), Trinity College, and National Science Foundation award DUE-1118600 (TUES).

\section{References}

1. Murray TA. Teaching students to read the primary literature using POGIL activities. Biochem Mol Biol Educ. 2014;42:165-73.

2. Rauschert ESJ, Dauer J, Momsen JL, Sutton-Grier A. Primary literature across the undergraduate curriculum: teaching science process skills and content: summary and comments from the workshop "101 ways to effectively use journal articles as teaching tools" presented at the 2011 ESA Annual Meeting. Bull Ecol Soc Am. 2011;92:396-405. 
3. Brownell SE, Price JV, Steinman L. A writing-intensive course improves biology undergraduates' perception and confidence of their abilities to read scientific literature and communicate science. Adv Physiol Educ. 2013;37:70-9.

4. Yeong FM. Using primary-literature-based assessments to highlight connections between sub-topics in cell biology. J NUS Teach Acad. 2013;3:34-48.

5. Forest K, Rayne S. Incorporating Primary literature summary projects into a first-year chemistry curriculum. J Chem Educ. 2009;86:592.

6. Round JE, Campbell AM. Figure facts: encouraging undergraduates to take a data-centered approach to reading primary literature. Cell Biol Educ. 2013;12:39-46.

7. Hoskins SG, Lopatto D, Stevens LM. The C.R.E.A.T.E. approach to primary literature shifts undergraduates' self-assessed ability to read and analyze journal articles, attitudes about science, and epistemological beliefs. Cell Biol Educ. 2011;10:368-78.

8. Gottesman AJ, Hoskins SG. CREATE cornerstone: introduction to scientific thinking, a new course for STEM-interested freshmen, demystifies scientific thinking through analysis of scientific literature. Cell Biol Educ. 2013;12:59-72.

9. Braun I, Nückles M. Scholarly holds lead over popular and instructional: text type influences epistemological reading outcomes. Sci Educ. 2014;98:867-904.

10. Committee on Professional Training. Undergraduate professional education in chemistry: ACS guidelines and evaluation procedures for bachelor's degree programs. ACS. 2008. http://www.acs.org/content/ dam/acsorg/about/governance/committees/training/2015-acsguidelines-for-bachelors-degree-programs.pdf. Accessed $25 \mathrm{Feb} 2015$.

11. Fang Z. Scientific literacy: a systemic functional linguistics perspective. Sci Educ. 2005;89:335-47.

12. Jacques-Fricke BT, Hubert A, Miller S. A versatile module to improve understanding of scientific literature through peer instruction. J Coll Sci Teach. 2009;39:24-32.

13. Broege AM. Primary literature can puzzle undergraduates: using the "jigsaw" to build understanding. Techniques in learning \& teaching. 2013. https://uminntilt.wordpress.com/2013/02/19/ primary-literature-can-puzzle-undergraduates-using-the-jigsaw-tobuild-understanding/. Accessed 3 Sept 2015.

14. Janicke-Butler D. Getting undergraduates to critically read and discuss primary literature. J Coll Sci Teach. 1997;27:29-32.

15. Shannon S, Winterman B. Student comprehension of primary literature is aided by companion assignments emphasizing pattern recognition and information literacy. Issues Sci Technol Lib. 2012;68. doi:10.5062/F4TB14TS

16. Sato BK, Kadandale P, He W, Murata PMN, Latif Y, Warschauer M. Practice makes pretty good: assessment of primary literature reading abilities across multiple large-enrollment biology laboratory courses. Cell Biol Educ. 2014;13:677-86.

17. Van Lacum E, Ossevoort M, Buikema H, Goedhart M. First experiences with reading primary literature by undergraduate life science students. Int J Sci Educ. 2012;34:1795-821.

18. Bogucka $\mathrm{R}$ et al. How to read scientific research articles: a hands-on classroom exercise. Iss Sci Technol Lib. 2009;59. doi:10.5062 F4S180FF.
19. Spiegelberg BD. A focused assignment encouraging deep reading in undergraduate biochemistry: a focused assignment to encourage deep reading. Biochem Mol Biol Educ. 2014;42:1-5.

20. McDonough V. Improving journal club: increasing student discussion and understanding of primary literature in molecular biology through the use of dialectical notes. Biochem Mol Biol Educ. 2012;40:330-2.

21. McCallum ML. A method for encouraging classroom discussion of scientific papers. Bull Ecol Soc Am. 2010;91:363-6.

22. Parachnowitsch A. Incorporating primary literature into courses. Teaching Tuesday. 2013. http://smallpondscience.com/2013/11/ 05/teaching-tuesday-incorporating-primary-literature-into-courses/. Accessed 4 Sept 2015.

23. Scott LK, Simmons SR. Incorporating primary literature in undergraduate crop science courses. J Nat Res Life Sci Educ 2006;35: 225-33.

24. Liotta LJ, Almeida CA. Organic chemistry of the cell: an interdisciplinary approach to learning with a focus on reading, analyzing, and critiquing primary literature. J Chem Educ. 2005;82:1794.

25. Bloom BS. Taxonomy of educational objectives: the classification of educational goals. New York: McKay; 1956.

26. Barkley EF, Cross KP, Major CH. Collaborative learning techniques: a handbook for college faculty. 1st ed. San Francisco: Jossey-Bass; 2005.

27. Wright S, Malcolm A, Wright C, et al. A microelectromechanical systems-enabled, miniature triple quadrupole mass spectrometer Anal Chem. 2015;87:3115-22.

28. Kovarik ML. In-class activity: interpreting the primary literature. Analytical Sciences Digital Library: Active Learning Materials. 2015. http://community.asdlib.org/activelearningmaterials/ interpreting-the-primary-literature/. Accessed 15 Dec 2015.

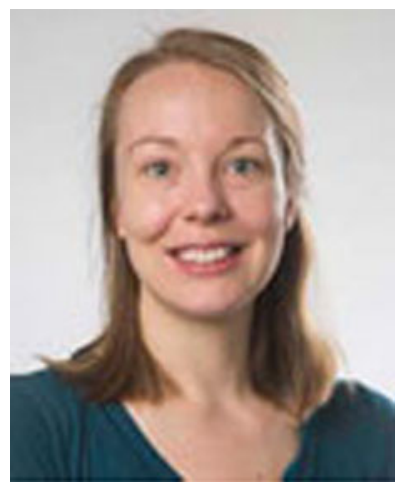

Michelle L. Kovarik is an Assistant Professor of Chemistry at Trinity College in Hartford, CT. Her research interests include microfluidics-based separations and single-cell assays; she pursues this research in collaboration with her undergraduate students. Other interests include active learning and novel pedagogical methods for analytical chemistry. She was a postdoctoral scholar in the Seeding Postdoctoral Innovators in Research and Education (SPIRE) program at the University of North Carolina and currently participates in the active learning group for the Analytical Sciences Digital Library. 